\title{
Perspective
}

PERSPECTIVE Actualité en histoire de l'art

2| 2013

Brasil

\section{O Barroco colonizador: a produção historiográfico- artística no Brasil e suas principais orientações teóricas}

Jens Baumgarten e André Tavares

\section{(2) OpenEdition \\ Journals}

Edição electrónica

URL: http://journals.openedition.org/perspective/5538

DOI: 10.4000/perspective.5538

ISSN: 2269-7721

Editora

Institut national d'histoire de l'art

Refêrencia eletrónica

Jens Baumgarten e André Tavares, « O Barroco colonizador: a produção historiográfico-artística no Brasil e suas principais orientações teóricas », Perspective [Online], 2 | 2013, posto online no dia 30 setembro 2014, consultado o 01 outubro 2020. URL : http://journals.openedition.org/perspective/ 5538 ; DOI : https://doi.org/10.4000/perspective.5538 


\title{
O Barroco colonizador: a produção historiográfico-artística no Brasil e suas principais orientações teóricas
}

\author{
Jens Baumgarten e André Tavares
}

\section{NOTA DO EDITOR}

Cet article existe en traduction française : Le baroque colonisateur : principales orientations théoriques dans la production historiographique

1 Os discursos pós-modernos e pós-coloniais abriram na historiografia européia e norteamericana novos espaços para publicações de áreas geográficas que por muito tempo foram consideradas secundárias. Com isso, objetos produzidos fora do cânone ocidental passaram a integrar uma história da arte mundial. A partir desse cenário, é importante repensar as consequências teóricas e metodológicas para a arte colonial, ou a chamada arte barroca, no Brasil. O presente artigo pretende, dessa forma, apresentar uma revisão historiográfica dessa área ${ }^{1}$, inserir essa bibliografia nos debates críticos atuais e, assim, apresentar uma visão geral a respeito dessa produção historiográfica, considerando que nenhuma subárea temática, cronológica e geográfica permite uma “ histoire totale" que englobe a produção completa.

\section{Arte colonial e/ou barroco: considerações metodológicas e teóricas}

2 O tema da arte colonial é indissoluvemente ligado ao discurso sobre o barroco. 0 termo começou a ser usado a partir do final do século xviII e se transformou em um conceito com as publicações de Cornelius Gurlitt e Heinrich Wölfflin, sobretudo com os livros Renascimento e Barroco, de 1888, e Conceitos Fundamentais da História da Arte, de 1915². 0 período conhecido como barroco, situado tradicionalmente entre os séculos XVII e XVIII, 
não pode ser visto apenas como um fenômeno histórico; esse termo refere-se à historiografia e, em especial, à história da arte, mas também à literatura. Nesse contexto, o barroco foi classificado como degenerescência (Jacob Burckhardt), como categoria estilística (Wölfflin), como alegoria (Walter Benjamin), como projeção do desejo (Germain Bazin) e foi relacionado à época contemporânea por meio do conceito de neobarroco (Omar Calabrese) ${ }^{3}$. Nos últimos anos, o uso do termo barroco passa por uma verdadeira "inflação" nas ciências humanas - e não apenas no Brasil.

3 Nesse país, esse conceito foi mais discutido no âmbito da teoria e da crítica literária, como mostra o debate entre Haroldo de Campos e João Adolfo Hansen (DE CAMPOS, 1979, 1989; HANSEN, 1992, 2003) e também a revisão crítica de Guilherme Gomes Júnior (GOMES JÚNIOR, 1998; sobre as artes plásticas, cf. p. 31-88). Apesar de ter sido aplicado tardiamente, o termo estilístico wölffliniano, que foi usado em várias circunstâncias como sinônimo de "arte colonial", teve muito sucesso na segunda metade do século xx. Enquanto o desenvolvimento desse conceito suscitou em países como o México, por exemplo, uma outra periodização e uma denominação mais política - a arte da conquista espanhola, a arte virreinal etc. -, no Brasil, a terminologia formalista domina o cenário até hoje.

4 O primeiro autor a mencionar esse assunto foi o pai da historiografia da arte brasileira, Manuel Araújo Porto-Alegre (1806-1879) que, ligado à tendência neoclássica dos pintores franceses que participaram da Missão Artística Francesa de 1816, analisou as obras da época colonial a partir de uma abordagem formal e política. Como ressalta Guilherme Gomes Júnior, “Além de ser provavelmente, no Brasil, o primeiro a utilizar a palavra barroca em um sentido estilístico, Porto-Alegre já esboça em suas reflexões uma teoria pendular da história da arte, baseada na ideia de um ir e vir entre formas clássicas e formas amaneiradas" (GOMES JÚNIOR, 1998, p. 41). Nesse sentido, é interessante constatar que o contexto da formação do Estado, a partir de meados do século XIX, também está vinculado ao tema estilístico apresentado por Wölfflin a respeito do desenvolvimento dos conceitos (WARNKE, 1989).

5 As traduções dos textos de Wölfflin exerceram grande influência sobre a produção literária e científica no Brasil. De acordo com João Adolfo Hansen: "Desde que Wölfflin usou o termo como categoria estética positiva, a extensão dos cinco esquemas constitutivos de 'barroco' - pictórico, visão em profundidade, forma aberta, unificação das partes a um todo, clareza relativa - passou a ser ampliada, (....) para em seguida classificar e unificar as políticas, as economias, as populações, as culturas, as 'mentalidades' e, finalmente, [as] sociedades europeias do século XVII, principalmente as ibéricas contrareformistas, com suas colônias americanas, na forma de essências: 'o homem barroco', 'a cultura barroca', 'a sociedade barroca' etc. Dedutivas e exteriores, as apropriações acríticas de Wölfflin substancializam a categoria, constituindo 'barroco' como fato e essência que existem em si" (HANSEN, 2003, p. 172-173).

6 No Brasil, o estilo barroco ganhou a partir da década de 1920, com o modernismo, uma importância predominante na construção de uma identidade cultural e estética própria - a chamada "brasilidade". o termo "barroco" provocou uma controvérsia, discutida até hoje, não somente por historiadores e críticos de arte. Assim como muitos outros artistas e críticos modernistas dos anos 1930, Mário de Andrade e seu aluno Luiz Saia viajaram a Minas Gerais e desenvolveram o conceito de uma arte brasileira nacional autóctone construída com base no "barroco de Minas" (barroco mineiro ; ANDRADE, 1928; 
GOMES JÚNIOR, 1998, p. 50-63; CHIARELLI, 2007, p. 69-96 et p. 247-248). A obra de Antônio Francisco Lisboa, o Aleijadinho, arquiteto e escultor da era colonial, serviu de evidência principal dessa arte, ainda que sua própria existência seja posta em dúvida por alguns críticos (CHIARELLI, 2007, p.173-175). Aleijadinho era o tema ideal para a apoteóse brasileira, uma vez que representava, por meio de sua própria personalidade, a mestiçagem por excelência. Apresentado como um artista autóctone que trabalhava no centro do Brasil, ele serviu de núcleo para o nascimento da nação brasileira e de sua representação artística, especialmente para os modernistas, mas também, principalmente na arquitetura, para os representantes do movimento neocolonial (movimento do final do século xx que deve ser diferenciado do movimento neobarroco da segunda metade do século $\mathrm{xx}$, caracterizado por abordagens transculturais e transhistóricas).

7 Por meio de suas interpretações podemos compreender o discurso renovador e emocional sobre a identidade nacional desenvolvido por Mário de Andrade em um artigo publicado em 1921 na crítica revista Ilustração Brasileira: "Mas o que há de mais glorioso para nós é o novo estylo néo-colonial, que um grupo de architectos nacionaes e portuguezes, com o Sr. Ricardo Severo à frente procura lançar (...) Não me consta que já tenha havido no Brasil uma tentativa de nacionalizar a architectura, estylizando e aproveitando os motivos que nos apresenta o nosso pequeno passado artístico, e formando construções mais adaptados ao meio. (...) o néo-colonial que por aqui se discute é infinitamente mais audaz e de maior alcance. Si o público, bastante educado, ajudar a interessante iniciativa, teremos ao menos para a edificação particular (e é o que importa) um estylo nosso, bem mais grato ao nosso olhar, hereditariamene saudoso de linhas anciãs e proprio ao nosso clima a ao nosso passado" (ANDRADE, 1921). Nesse contexto, temos que distinguir, juntamente com Maria Lúcia Bressan, que estudou o modernismo e a proteção do patrimônio nos debates culturais da década de 1920 (BRESSAN, 1997, 2011), o entusiasmo de Mário de Andrade e sua busca de raízes nacionais, que caracterizaram o movimento modernista brasileiro, do conservadorismo de Ricardo Severo, que aderiu ao neobarroco e defendeu a reavaliação da ideia de pátria como reação ao cosmopolitismo destrutivo que, em seu ponto de vista, ameaçava a sociedade paulista nas primeiras décadas do século XX (AMARAL, 1994, p. 150-152). Nesse sentido, a elite paulista defendia a ideia de que o neobarroco ou o neocolonial poderia funcionar como um apelo afirmativo com seu caráter de "bastião dos valores nacionais" que evitaria a ameaça representada pelo grande fluxo de imigrantes europeus, principalmente italianos, que se estabeleceram na região nesse período. Houve, assim, uma mescla e uma justaposição de discursos ideológico-políticos e estéticos com relação à ideia de "nação" e o desejo de uma reafirmação social: os "paulistas quatrocentões" contra os "novos ricos sem pátria".

8 Uma nova reflexão sobre o barroco começou a ser desenvolvida nos anos 1940 pela historiadora da arte Hannah Levy ${ }^{4}$, que introduziu os conceitos do barroco e ajudou divulgá-los por meio do Serviço do Patrimônio Histórico e Artístico Nacional (Sphan), onde trabalhou a convite do diretor Rodrigo Melo Franco de Andrade. Originária da Alemanha, ela emigrou em 1934 para Paris, onde publicou sua primeira crítica aos conceitos wölfflinianos baseada na sociologia da arte (LEVY, 1936) e, em seguida, instalou-se no Rio de Janeiro, onde trabalhou no Instituto do Patrimônio Histórico e Artístico. Ela publicou, então, na revista do Sphan, uma série de artigos teóricos dedicados principalmente aos estudos da história do barroco no Brasil (LEVY, 1940, 1941, 
1942, 1944, 1945), nos quais propôs uma releitura com o propósito de estabelecer novas abordagens para a análise de obras artísticas da época colonial ${ }^{5}$. Ela sintetizou metodologicamente abordagens tradicionais, criticando-as por meio da experiência da "instabilidade" (referimo-nos aqui ao conceito desenvolvido por Moser in MOSER, 2001). O trabalho realizado por Levy nos anos 1940 foi bastante notável já que a arte nãoeuropeia não dispunha de nenhum destaque na história da arte acadêmica na primeira metade do século $\mathrm{xx}$, ao contrário da arte moderna, que tinha alguns de seus representantes ocupando cargos de curadores de museus e de críticos de arte ${ }^{6}$.

Para compreender o trabalho de Levy, é importante mencionar a tese de doutorado que a historiadora da arte defendeu em Paris sob orientação de Charles Lalo e Henri Focillon e que foi publicada em 1936 por uma pequena editora judaico-alemã - fato que não permitiu a divulgação merecida da obra, nem mesmo após a Segunda Guerra Mundial (LEVY, 1936; BELow, 2005). Nesse estudo, ela avalia o pensamento e a análise científica de Heinrich Wölfflin e de seus precursores, Konrad Fiedler, Adolf Hildebrandt e Jacobr Burckhardt, perante o cenário de desenvolvimento social e econômico de sua época. Seu enfoque baseia-se em uma metodologia fundamentada no marxismo dialético de Max Raphael e contempla também as posições de autores alemães como Max Horkheimer, Walter Benjamin, Karl Mannheim, Erwin Panofsky e Edgar Wind, além, é claro, de seus professores e orientadores na Sorbonne. Apesar da grande estima que exprime por Wölfflin em sua tese e a despeito do grande sucesso que ele havia conquistado com a publicação de Renascença e Barroco e de Conceitos fundamentais da história da arte, ela não deixa de criticar enfaticamente as suas posições. A recepção de Conceitos, que pode ser vista como a publicação de história da arte mais bem sucedida (considerando o número de traduções e reedições que ela obteve), não somente no Brasil, mas no mundo inteiro, ainda não foi analisada detalhadamente.

Destacando a importância de Wölfflin para o processo de cientificação da história da arte e a relevância de suas análises de obras singulares, a crítica de Levy concentra-se no conceito idealístico da história. Ela destaca sobretudo o enfoque de Wölfflin, que defende uma história independente da observação e autônoma em relação aos desdobramentos artísticos; isso sublinha também a rejeição de um estilo uniforme e homogêneo em uma época constituída e modificada pelas noções de nação e raça. Segundo Levy, a história deve ser entendida como um processo dialético no qual as diferentes esferas culturais dispõem a princípio de uma dinâmica própria, vinculadas, porém, à história social. Desse modo, a reflexão acerca da relação entre arte e sociedade precisa ser aplicada às análises de obras singulares, à conceituação das épocas da história da arte e às instituições das artes e ciências. A temática dos artigos publicados na revista do Sphan, além de ser inédita, representou um progresso na teoria e na metodologia da disciplina. Em seus dois primeiros artigos sobre o "valor artístico e o valor histórico", bem como nos textos acerca das três teorias do barroco (LEVY, 1940, 1941), Levy esboçou as linhas gerais da sua metodologia. Seus três últimos artigos apresentam, por sua vez, suas ideias sobre a arte colonial do Rio de Janeiro e de Minas Gerais (LEVY, 1942, 1944, 1945).

11 Segundo Levy, uma obra de arte que desencadeou a formação de uma "escola" no Brasil colonial possui um valor histórico inerente, sem que tenha obrigatoriamente um valor artístico. A esses dois valores, soma-se também o de documentação, que se aplica às representações de eventos importantes da história brasileira (LEVY, 1940). A distinção em si desses três valores não é inovadora, mas o texto de Levy ressalta que eles "não 
constituem, na historia concreta, valores absolutos, mas, relativos" (LEVY, 1940, p. 188). Ao dar prosseguimento à sua tese, ela critica também o eurocentrismo: "Esse sentido relativo dos valores evidencia-se se considerar uma obra (sucessivamente) em relação à produção total de um só artista, a uma escola local, à história da arte de um país ou à história mundial da arte, etc." (LEVY, 1940, p. 188). Essa citação revela também um outro aspecto do pensamento e da linguagem da autora: ela evita mencionar termos como "nação" ou "nacional", contrariamente a modernistas como Mário de Andrade e a historiadores da arte como Lourival Gomes Machado, que, na busca pela nacionalidade, falam da "nossa cultura" e constroem a brasilidade a partir da arte colonial de Minas Gerais. Citando os possíveis padrões de julgamento, ela se posiciona em relação às críticas: "Esta verificação não implica absolutamente, [c]omo consequência pela impossibilidade de qualquer julgamento, uma vez que 'tudo é relativo'. Trata-se apenas de delimitar exatamente o alcance (concreto e teórico) do juizo expendido" (LEVY, 1940, p. 189).

12 A importância desse enfoque para a arte brasileira, latino-americana ou até mesmo para a arte mundial reside uma vez mais nas pré-valorizações. Levy demonstra que "a simples verificação da influencia exercida por uma determinada obra sobre outra não contem em si nenhum julgamento de valor. Somente um estudo minucioso relativo tanto à análise da estrutura artística interna e à análise histórica da obra que exerceu influência como da obra que a sofreu decidirá a questão de saber que valor (histórico ou artístico) se deve atribuir a uma e outra das duas obras" (LEVY, 1940, p. 190-191). Ao abordar a arte brasileira livre de qualquer preconceito, ela observa que a constatação da existência de uma influência européia não possui nenhum significado: "Se amanhã um historiador trouxesse a prova irrefutável de que existe uma influência certa de tal obra de determinado artista europeu sobre as estátuas dos profetas de Congonhas, este fato seria certamente de grande interesse sob muitos aspetos. Mas o fato dessa influência em si não dirá jamais nada do valor histórico ou do valor artístico da obra de Antonio Francisco Lisboa" (LEVY, 1940, p. 191). Com essa posição, Levy questiona a primazia de uma história da arte europeia sobre uma história da arte não-europeia. Seu ponto de vista direciona-se implicitamente ao interesse na relação entre centro e periferia - questão igualmente presente nas ideias de George Kubler (KUBLER, 1959, 1962) e discutida contemporaneamente por Thomas DaCosta Kaufmann no debate sobre os conceitos de uma nova geografia da arte (KAUFMANN, 2004). Nesse sentido, ela quebra as hierarquizações sem perder o foco da obra singular e de seu contexto individual, como demonstra nos artigos sobre a pintura mineira e carioca.

13 O clima de meados do século xx pode ser reconstruído ao citarmos Lourival Gomes Machado e seus diversos ensaios que foram reunidos e publicados sob o título de Barroco Mineiro (GOMES MACHADO, 1969 ; cf. também GOMES JÚNIOR, 1998, p. 76-87) e a já mencionada Hannah Levy, com o artigo "A Propósito de Três Teorias Sobre o Barroco" (LEVY, 1941) - dois pesquisadores que sintetizaram as principais linhas de argumentação das teorias explicativas sobre o barroco. Em seu artigo "Modelos europeus na pintura colonial", publicado em 1944, Levy afirma que não há dúvida de "que grande número de pintores nacionais se utilizou de modelos da arte europeia. Daí o caráter eclético da pintura colonial, vista em conjunto, e daí também o caráter heterogêneo que se nota frequentemente nas obras de um mesmo artista" (LEVY, 1944, p. 64). Gravuras de diferentes origens (tanto em termos artísticos quanto cronológicos), principalmente alemãs e flamengas, por exemplo, foram indistintamente usadas como modelos por 
artistas de Minas Gerais. Resumindo suas observações, Levy destaca que se o pintor colonial copiou fielmente o modelo no que se refere à composição, à distribuição dos tons luminosos e sombrios, às atitudes, aos objetos menores, à indumentária, etc., observa-se igualmente uma redução parcial da cena quanto ao número de figuras representadas, bem como uma simplificação parcial dos fundos. Os gestos expressivos foram minuciosamente conservados pelo copista. Na opinião de Levy, "os painéis traduziram perfeitamente o caráter dramático e agitado das representações gravadas [...] ou ainda ofereceram até um efeito mais dramático de que o das próprias gravuras originais [...]. Por outro lado, a impressão de agitação suscitada pelas pinturas resulta, também, da circunstância de haver o pintor, simplificando os fundos, concentrado [....] todo o interesse sobre as figuras humanas" (LEVY, 1944, p. 48-49). Sem aprofundar-me nesse tema nem criticar suas observações, entendo que precisamos levar em consideração os pressupostos conceituais de seu pensamento: Levy aplicou, em suas análises de obras singulares, o método de Wölfflin aos exemplos brasileiros, abrindo-o porém a abordagens sociológicas. Além disso, suas análises dão início a uma ruptura com o esquema dicotômico que distingue uma cultura produtiva e uma cultura receptiva.

Duramente criticados por Lourival Gomes Machado como sendo uma simples vulgarização das abordagens de Wölfflin e Leo Balet, por exemplo, (MACHADO, 1969, p. 46) ${ }^{7}$ os trabalhos Hannah Levy ultrapassam claramente o âmbito de uma simples apresentação e revelam sua preferência pelos métodos sociológicos na análise do contexto colonial do Brasil: "A teoria de Balet [...] explica os fenômenos artísticos pelas suas relaç[õ]es [c]om a totalidade das condições históricas existentes numa época determinada, [isto] nos parece ser, por isso mesmo, a [forma] mais apta a resolver também os problemas da historia da arte brasileira" (LEVY, 1941, p. 284). Específica a uma história da arte brasileira, a metodologia desenvolvida por Levy emancipou-se das abordagens europeias, sem no entanto enveredar-se pelo caminho de uma história da arte nacional ou mesmo nacionalista, em busca da essência de uma arte nacional, nos termos defendidos por Mário de Andrade e pelos adeptos da brasilidade. Ela não somente questionou o cânone europeu, mas também defendeu a importância da conceituação teórica para uma história da arte não-nacionalista e não-eurocentrista. Esse enfoque é particularmente interessante por não rejeitar a princípio as posições de fundadores da disciplina, como Wölfflin ou Max Dvořák. Ao defender as análises estruturais e formais das obras, ela revela as hierarquizações e as pré-valorizações dessas abordagens formalistas, em uma perspectiva que em décadas posteriores recebeu o nome de "crítica da ideologia" (Ideologiekritik), conceito desenvolvido pelos neomarxistas e pelos membros da Escola de Frankfurt. Neste sentido, é possível considerar Levy como uma das predecessoras de uma história da arte pós-colonial.

Um discurso nesses termos contrariava necessariamente os diversos discursos oficias sobre a arte do século xvIII que vinham sendo sedimentados no Brasil desde os anos 1950 por meio da intervenção de um outro autor fundamental para a divulgação do assim chamado barroco brasileiro: Germain Bazin. O trabalho de Bazin, que oferece uma síntese da produção artística, sobretudo arquitetônica, inclui um esforço interpretativo mais amplo e, ao mesmo tempo, uma análise do patrimônio artístico organizada por estados brasileiros. $O$ autor valeu-se de investigações anteriores, como as realizadas por Raimundo Trindade ou Fernando Pio (PIO, 1957 ; TRINDADE C., 1958), que estavam ligadas mais ao âmbito religioso e à história da Igreja Católica no Brasil do que 
ao universo da história da arte. Ao dedicar-se a Aleijadinho em 1963, Bazin retornou ao tema do artista símbolo do barroco nacional brasileiro e estabeleceu, assim, a continuidade das pesquisas sobre essa temática, pavimentando o caminho para pesquisadores que ampliaram a investigação, como é caso da imensa contribuição de Myriam Andrade Ribeiro ou de Lélia Coelho Frota (cf., entre outros, FROTA, 1982 ; OLIVEIRA, 2003).

Os textos de autores que se defrontaram com o problema da preservação e sobretudo do estabelecimento de critérios para a "estabilização" da imagem (em referência à "instabilidade ontológica" de Moser, cf. MOSER, 2001) e para o restauro das cidades históricas brasileiras são também profundamente relevantes. Os textos científicos, assim como todo o material de estudo - incluindo cartas, desenhos, levantamentos e rascunhos - de Lucio Costa, Paulo Santos e Sylvio de Vasconcellos (SANTOS, 1951, 2001 ; VASCONCELLOS, 1968 ; COSTA, [1941] 1997) constituem uma fonte incontornável para a compreensão do processo de criação de um projeto de gestão do patrimônio artístico barroco no Brasil. Essas personalidades marcantes - cada uma a sua maneira combinaram o trabalho de pesquisa com a intervenção em projetos concretos. Suas ações extrapolam a atividade acadêmica e reforçam uma tendência fortemente arraigada na cultura brasileira: a fusão da formação em arquitetura com a ideia de salvaguarda do patrimônio. Particularmente no caso de Lucio Costa, o interesse pela arte colonial converteu-se em uma forma moderna de reabilitação do barroco, em uma ponte hermenêutica que se assemelha à apropriação modernista dos artistas mineiros pela vanguarda paulista dos anos 1920.

17 Nos últimos anos, uma das publicações mais polêmicas sobre a arte colonial retomou os estudos desde o século XIX sobre o personagem central glorificado pelos modernistas, o Aleijadinho. Em sua tese de doutorado, publicada com o título de $O$ Aleijadinho e o aeroplano, Guiomar de Grammont desconstrói os atos que, segundo ela, inventaram a figura do artista a partir de fontes duvidosas (GRAMMONT, 2008). Não por acaso, a pesquisa se inscreve no campo dos discursos literários e apresenta uma abordagem de tradição francesa, evidenciada pela escolha de seus orientadores, João Adolfo Hansen e Roger Chartier. A pesquisa inclui também reflexões desenvolvidas por Ângela Brandão (BRANDÃO, 1998) e por Sônia Fonseca, em sua polêmica dissertação de mestrado (FONSECA, 2001), na qual sugere que o modelo utilizado por Rodrigo Bretas para a elaboração de sua pioneira biografia sobre Aleijadinho no século xIX teria sido o personagem do Quasímodo do romance Notre Dame de Paris, de Victor-Hugo. O texto de Grammont foi criticado, sobretudo pelos historiadores mineiros, por não considerar os estudos de caso dedicados a essa região, que, embora não tenham sido amplamente divulgados por meio de edições comerciais - como de praxe nas universidades brasileiras -, são disponibilizados nas bibliotecas universitárias ou, mais recentemente, em bancos digitais que dão acesso a teses e dissertações acadêmicas. A crítica veio também de agentes envolvidos com o mercado de arte, no qual a confirmação de autenticidade de uma obra de Aleijadinho pode facilmente multiplicar o seu preço.

De maneira geral, as publicações sobre a arte colonial podem ser divididas em três eixos: pesquisas formais e estilísticas; pesquisas históricas e/ou iconográficas; pesquisas teóricas e/ou de tradição literária. Em todos os casos, os diferentes aspectos das discussões sobre a arte colonial no contexto dos territórios espanhóis e dos discursos em torno da chamada "arte mundial" não foram amplamente recebidos. Nos últimos anos, o efeito da globalização não somente para a economia e para a sociedade, mas 
também para as ciências humanas, tem sido tema de infindáveis discussões. Esse fenômeno da "virada pós-colonial" foi marcado sobretudo pelas obras de Edward Said sobre o orientalismo e de Homi Bhaba acerca da nação, da narração e dos lugares de cultura $^{8}$. No âmbito da história da arte, essa discussão considerou problemático o eurocentrismo e passou a buscar uma reformulação, que se consolidou com o conceito de arte mundial e, por conseqüência, com a criação de uma história da arte mundial. Inúmeros congressos na Europa e nos Estados Unidos refletiram a respeito dessa reforma e várias instituições, tais como o Getty Institute, em Los Angeles, e outros órgãos universitários, respondem a essa nova demanda. $O$ congresso internacional do Comitê Internacional de História da Arte (CIHA), ocorrido em 2008 em Melbourne, por exemplo, teve como tema "Crossing Cultures: Conflict, Migration and Convergence" . Dentre as inúmeras publicações sobre o tema, é necessário mencionar as obras de David Summers, Real Spaces: World Art and the Rise of Western Modernism, publicada em 2003, e de Thomas DaCosta Kaufmann, Towards a Geography of Art, publicada em $2004^{10}$. Ambas as abordagens não somente ampliaram o cânone da história da arte tradicional, como também defenderam a importância de uma revisão teórica e metodológica. Nesse contexto, o enfoque de George Kubler (KUBLER, 1959, 1962), que buscou estabelecer uma geografia da arte na historiografia da arte dos territórios latino-americanos, serviu de base à referida obra de Thomas DaCosta Kaufmann. Paralelamente a essas publicações, várias iniciativas, incluindo exposições e a criação de novos cursos e departamentos de história da arte no Brasil, permitiram uma reformulação da categoria da arte colonial, que até então era considerada uma subárea.

\section{O Barroco em transformação: do local ao global e todo o caminho de volta}

Em 2002, uma grande exposição dedicada à produção artística brasileira foi inaugurada no Guggenheim Museum, em Nova York. No amplo vão livre do edifício, iluminado de modo dramático para a ocasião, brilhava, contra a penumbra, a madeira coberta de folhas de ouro do altar do Mosteiro de São Bento de Olinda. A exposição Brazil: Body and Soul (Brazil, 2001) reafirmava algumas das chaves de interpretação da produção artística do séculos XVII e XVIII, a saber o sincretismo dos artefatos religiosos e dos objetos litúrgicos e ex-votos, a conexão com o modernismo e com a vanguarda nacionalista de inícios do século xx e as ressonâncias na arte popular, indígena ou africana, tudo celebrando a invenção de uma arte local, original e nova que tinha encontrado na talha e na escultura setecentistas seu âmbito de maior experimentação. A exposição acertou na seleção de imagens processionais, indicando a importância dos rituais religiosos públicos e da dramatização sacra dos espaços urbanos, e sublinhou as singularidades notáveis de artistas como Francisco Xavier de Brito, Inácio Manuel da Costa e Aleijadinho.

20 A mostra do Guggenheim, entretanto, não foi um fato isolado; ao contrário, ela encerrava um período de reinvenção da ideia do barroco brasileiro que, desde 1998, vinha sendo revisitado no Brasil em mostras mais ou menos espetaculares (sobre os usos do conceito de barroco nessas exposições, cf. MORESCHI, 2004). Naquele ano, a exposição $O$ Universo Mágico do Barroco (O Universo..., 1998) celebrava e exibia a profusão inventiva da escultura, da pintura, dos ornamentos corporais - como como colares, brincos e pingentes característicos das baianas (os balangandãs) - além da prataria 
litúrgica das credências, dos crucifixos, dos tocheiros e das palmas. Ali, igualmente, reafirmava-se alguns dos argumentos centrais do pensamento sobre esse barroco local e ideal, forma característica de um hipotético ethos brasileiro. A exposição destacava a continuidade do barroco ao longo dos séculos xIX e Xx, sobretudo por meio dos rituais, das festividades religiosas, do sistema social das irmandades e de seu programa iconográfico e simbólico. A ideia era, em parte, retomar uma hipótese similar aventada na excepcional mostra Tradição e Ruptura: síntese da arte e cultura brasileira, realizada em 1984 no pavilhão Ciccillo Matarazzo, no Parque do Ibirapuera, com curadoria do literato e historiador da arte Alexandre Eulálio (Tradição e Ruptura, 1984).

21 Em 2000, na ocasião da celebração dos quinhentos anos do descobrimento do Brasil ápice desse movimento de revisão - foi organizada uma gigantesca mostra que recuperava, ao menos em duas seções - Arte barroca (Arte barroca, 2000) e Negro de corpo e alma (Negro de corpo..., 2000) - aspectos vitais da tradição escultórica religiosa desenvolvida no Brasil. Se a primeira seção, cujo catálogo foi assinado por Myriam Ribeiro A. de Oliveira, buscava definir as declinações e as "maneiras" locais, assim como as soluções formais características de cada uma das regiões brasileiras ao longo do século XVIII, a segunda organizava-se em torno do argumento étnico e do tema da contribuição africana à cultura brasileira. Fruto do trabalho do artista e curador Emanoel Araújo e da coleção por ele constituída, as peças dessa seção deram origem ao Museu Afro Brasil, em São Paulo. Embora não seja constituída especificamente de obras do século XVIII, essa coleção é uma das mais bem sucedidas para a visualização dessa "fronteira" entre as mãos africanas e as convenções de representação portuguesas. A imagem de devoção popular, os santos negros representados em esculturas do século XVIII e os diversos ex-votos em pintura sublinham o encontro dessas práticas representativas.

A quarta Bienal de Arquitetura de São Paulo, realizada em 1999, e a exposição Robert Smith: investigação na história da arte (Robert C. Smith, 2000) permitiram reintroduzir no circuito brasileiro o acervo desse historiador norte-americano, nome essencial para a definição e para o estabelecimento de uma terminologia específica para a análise da produção em talha decorativa em Portugal e no Brasil. Seus cadernos de notas, suas fotografias e sua correspondência oficial foram expostos, revelando assim aspectos diversos da construção da análise estilística no Brasil. A bienal dedicou igualmente à produção arquitetônica brasileira uma ampla exposição retrospectiva, organizada por Roberto Montezuma e intitulada Arquitetura Brasil 500 anos: uma invenção recíproca, apresentada em seguida no Museu de Arte Moderna de Recife, em 2000 (MONTEZUMA, 2002). Na mesma época, Rogério Amorim do Carmo, da Universidade Federal Juiz de Fora, apresentou um trabalho universitário intitulado Ouro Preto: experiência imaginária da paisagem e gesto projetual, dedicado a um dos temas mais candentes do cenário brasileiro, a saber, como projetar uma nova arquitetura para os centros históricos ditos barrocos - um tópico que até hoje ainda não foi resolvido a contento (CARMO, 1999).

23 A partir dos anos 1990, entretanto, estabeleceu-se no Brasil um forte movimento de recuperação filológica das poéticas desenvolvidas entre os séculos XVI e XVII. Esse interesse pela preceptiva e pelas retóricas do primeiro período moderno nasce, em sua grande maioria, nos estudos literários e dele estende-se aos demais campos de estudo da produção artística. o livro Guilherme Simões Gomes Júnior, Palavra Peregrina: o barroco e o pensamento sobre artes e letras no Brasil, publicado em 1998, é um testemunho dessa nova análise do período em questão que nasce na literatura (GOMES JÚNIOR, 1998). 
Entre as considerações originais do texto, encontra-se a sistematização pioneira da historiografia do barroco luso-brasileiro que incorpora de um modo mais consistente os debates do século xIx. Ele destaca também as peculiaridades de percepção sobre a herança dos séculos de colonização em contraste com certo discurso hegemônico sobre as artes do século XviII, sobretudo a partir da fundação do Serviço de Patrimônio Histórico Nacional, em 1937.

Os trabalhos de João Adolfo Hansen e de Adma Muhana, ambos vinculados à Faculdade de Filosofia, Letras e Ciências Humanas da Universidade de São Paulo, ou de Alcir Pécora, do Instituto de Estudos Linguísticos da Universidade Estadual de Campinas, são de grande relevância para a afirmação dessa corrente. Suas contribuições têm sido capitais para a reconstrução das mentalidades e da sensibilidade dos séculos XVII e XVIII, ainda que abordem poesia, história ou teoria literária, em obras como A Sátira e o Engenho (HANSEN, 1989) e Alegoria (HANSEN, 1987), Máquina de Gêneros (PÉCORA, 2001) e Teatro do Sacramento (PÉCORA, 1994) ou Poesia e Pintura ou Pintura e Poesia (MUHANA, 2002, reedição comentada de um tratado português seiscentista de autoria de Manuel Pires de Almeida).

O estudo da história literária, e em particular da figura de Antônio Vieira e de seus sermões, teve um efeito subsidiário bastante relevante no âmbito da investigação artística. Personagem de biografia complexa, que se desenvolveu em territórios geográfica e simbolicamente diversos, Vieira transitou entre Roma, Lisboa, Maranhão e Salvador. O interesse pela sua trajetória colocou em questão a relevância da ressonância internacional dessa literatura, mas também de suas conexões com os meios eruditos europeus, particularmente com os modelos romanos e com a sua difusão na Península Ibérica e, daí, para as Américas. Fala-se não apenas da aplicação de modelos artísticos italianos em Portugal ou, mais tarde, da utilização de modelos originários da Áustria ou da Europa central no mundo português, mas também dos processos de apropriação e transformação desses modelos e dessas fontes visuais pelo ambiente artístico local assim como da transferência de mão de obra artística qualificada e de obras entre os grandes centros e o circuito ibérico de modo geral. A força e o significado do sermão entre os séculos XVII e XVIII, bem como dos aparatos visuais dispostos em torno do predicador e das circunstâncias da prédica - o púlpito, o gestual, o concurso de pinturas e de outras imagens - inspiraram trabalhos como o de Marina Massimi acerca dos usos da imagem ou do conceito de memória nos sermões de Vieira (MASsimI, 2012). Também renovaram o interesse pela obra de Eusébio de Mattos, recentemente recuperada em edição contemporânea - ao menos sua coletânea de sermões Ecce Homo (мATOS, 2007a; cf. também matos, 2007b) - por Américo Miranda, Valéria M. P. Ferreira e pela já mencionada Adma Muhana (MUHANA, 2002).

Ainda no campo da literatura e da investigação sobre a sensibilidade específica do período, podemos citar os trabalhos de Ivan Teixeira. Suas pesquisas concentraram-se na compreensão do mecenato artístico e literário durante a segunda metade do século XVIII, período conhecido como Pombalino, em alusão ao reinado de D. João I e ao seu primeiro ministro, Sebastião José de Carvalho e Melo, o Marquês de Pombal. Seu livro Mecenato Pombalino de Poesia Neoclássica (TEIXEIRA, 1999) não apenas faz uma introdução à poética neo-horaciana que caracteriza a criação literária luso-brasileira do período, mas também apresenta uma época de intensas mudanças no campo político e pedagógico. Entre essas transformações, que tiveram grande influência para a produção artística, estão a expansão urbana na colônia brasileira e a demarcação efetiva do 
território, após disputas com a Espanha, com a assinatura, em 1750, do Tratado de Madri, que definiu as fronteiras com a América espanhola, assim como a expulsão dos Jesuítas, em 1759. Nesse campo, os trabalhos da historiadora estadunidense Roberta Marx são também bastante relevantes, ao lado de obras clássicas nessa área no Brasil, como as de Paulo Santos (SANTOS, 2001), Nestor Goulart Reis Filho (REIS FILHO, 2000, 2001) e Maria Helena Ochi Flexor (FLEXOR, 1974, 2011).

$\mathrm{Na}$ faculdade de arquitetura da Universidade Federal da Bahia, em Salvador, estabeleceu-se uma ampla tradição de estudos ligados à história do urbanismo no período colonial, associados aos cursos de restauro do patrimônio imóvel, um dos mais importantes do Brasil. Eugênio de Ávila Lins bem como Paulo Ormindo Azevedo estão ligados a esse grupo. Os trabalhos de José Luís da Mota Menezes (menEzes, 1984, 1988), Fernando Guerra (GUERRA, 1989), Leonardo Dantas (DANTAS, 2004) e Fernando Ponce de Leon (LEON et al., 1998), todos de Pernambuco, também merecem ser citados. Este último é autor de um valioso guia bibliográfico da arte luso-brasileira, escrito em colaboração com Lúcia Gaspar (LEON, GASPAR, 1998).

Os estudos urbanísticos, campo autônomo na tradição historiográfica e artística brasileira, encontram no período colonial um amplo campo de investigações. Textos como os de Cláudia Damasceno Fonseca, Des Terres aux villes de l'or (FONSECA, 2003), ampliam as pesquisas sobre a formação das cidades durante o ciclo da mineração em Minas Gerais e propõem avanços no campo da análise da cartografia e da iconografia urbanas, deslocando-as de certa função ilustrativa para uma posição de protagonismo que estrutura os argumentos da autora. O tema dos possíveis modelos europeus utilizados na arquitetura da segunda metade do século XVIII - particularmente sensível em regiões como Minas Gerais, Rio de Janeiro e Pernambuco - foi abordado por Rodrigo Espinha Baeta, da Universidade Federal da Bahia, em seu livro Barroco, a Arquitetura e a cidade nos séculos XVII e XVIII (BAETA, 2010).

$O$ estudo de Baeta reorganiza, aprofunda e discute ideias presentes em obras anteriores capitais, como é o caso de $O$ Rococó religioso no Brasil e seus antecedentes europeus, de Myriam R. A. de Oliveira (olveira, 2003), ou de "Medieval ou Barroco: proposta de leitura da cidade colonial", um pequeno, mas precioso artigo com título provocador, que reúne as seminais intuições da pesquisadora italiana Giovanna Rosso del Brenna e que foi em publicado na Revista Barroco, da Universidade Federal de Minas Gerais veículo essencial para a definição desse campo de estudos no Brasil a partir dos anos 1970 (BRENNA, 1982-1983). Superando a eterna discussão entre os modos portugueses e espanhóis de planejar a cidade e ocupar o território - tópico analítico que ganha contornos precisos em Raízes do Brasil, de Sérgio Buarque de Holanda (BUARQUE DE HOLANDA, 1936) -, Del Brenna aponta um novo modo de agir sobre o território baseado em uma concepção de cenografia urbana que, sobretudo no século xvIII, assume uma função simbólica particular.

Para além do âmbito específico do planejamento urbano estrito, o tema da cenografia urbana, baseado em estudos de caso, superpondo legislação, regulamentação e políticas urbanas, mas fundamentado também na análise de uma cultura visual para a cidade que inclui as múltiplas tradições de vedutistas e pintores de paisagem, foi mencionado pelos historiadores portugueses do urbanismo e da arquitetura Walter Rossa e Paulo Varela Gomes (GOMES, 1988 ; ROSSA, 2002) em estudos que influenciaram a percepção geral sobre as cidades do Brasil colonial. Rodrigo Almeida Bastos contribuiu de forma relevante 
para a compreensão da retórica aplicada à história do urbanismo colonial no Brasil com o seu livro A maravilhosa fábrica de virtudes: o decoro na arquitetura religiosa de Vila Rica, Minas Gerais (1711-1822), que articula elementos de tratadística, crônica e história urbana. $O$ autor oferece uma superposição sensível da vertente filológica com certa história das mentalidades aplicada às cidades e à ornamentação do território no século XVIII (BASTOS, 2009).

31 A tradição historiográfica paulista dedicada à arquitetura urbana é igualmente ampla. Ela inclui trabalhos de fôlego sobre a tipologia específica das residências e dos edifícios civis na região de São Paulo, como é o caso dos textos de Luís Saia (SAIA, 1978), Carlos Lemos (LEMOS, 1979, 1999), Dalton Sala e, em tempos mais recentes, Paulo Garcez (MARINS, 2001 ; Aleijadinho..., 2002). Aracy Amaral nos legou um instigante estudo acerca da produção arquitetônica paulista e suas possíveis conexões com a arquitetura da América espanhola (AMARAL, 1981). Nele, ela desenvolve o importante tema das rotas comerciais sul-americanas, dos encontros e dos confrontos entre portugueses e espanhóis durante os anos da colonização e de seu impacto na produção artística, o que constitui atualmente um campo de pesquisa em plena expansão. Ao sul do Brasil, na área de confronto com a cultura espanhola, é preciso destacar a produção pioneira de Eduardo Etzel, que mapeou o território de expansão urbana e artística do Brasil meridional em seus textos dos anos 1970 (ETZEL, 1974).

O estudo de caráter estilístico mais estrito ampliou-se no Brasil igualmente a partir dos anos 1990. As pesquisas sobre o trânsito de objetos entre Portugal e a América portuguesa, indicando de modo preciso as trajetórias pelo Atlântico de artefatos, livros, gravuras e imagens religiosas, encontram-se em ainda em fase de consolidação, mas têm ganhado crescente complexidade. A identificação de processos de transferência formal via gravuras, livros e desenhos, bem como por meio de agentes efetivamente identificáveis, ganha relevância em estudos como o de Luís Alberto Ribeiro Freire acerca da renovação da talha decorativa na Bahia entre os séculos XVIII e XIX. O seu livro A Talha Neoclássica na Bahia (FREIRE, 2006), além de apresentar uma precisão documental no que tange à identificação das alterações dos modelos ornamentais e do processo de organização das oficinas de artistas e artífices na região de Salvador, pode ser lido igualmente como um estudo sobre o gosto e sobre as relações de mecenato durante o início do século XIX.

No campo das pesquisas sobre arte produzida ou presente em acervos setecentistas no Brasil, há ainda grandes áreas a serem estudadas principalmente em relação ao mobiliário e ao design. Estudos precursores como Mobiliário Baiano, da já mencionada Maria Helena Flexor (FLEXOR, 2009), foram retomados em trabalhos como os de Ângela Brandão, dedicados à investigação da mobília pertencente à antiga arquidiocese da cidade de Mariana, no estado de Minas Gerais. Metodologicamente, a história do colecionismo de mobília e da relação entre a mobília e a talha decorativa religiosa parte essencial da produção dos entalhadores na América portuguesa - requer o exame de toda a documentação de inventários, testamentos e registros cartoriais, de cartas pastorais e de registros de encomendas e despesas com esse gênero de aparato luxuoso - documentos conservados em arquivos como o da arquidiocese de Mariana, da Casa Setecentista, na mesma cidade, ou o da Casa do Pilar, em Ouro Preto, antiga Vila Rica. No caso brasileiro, a dispersão dos acervos e a ausência de estudos consistentes sobre as suas proveniências dificultam sobremaneira a recomposição dos conjuntos antes dispostos em um mesmo ambiente. 

oratórios brasileiro, séculos XVIII e XIX, de Silveli Toledo Russo, seguem o mesmo caminho (RUsso, 2010). Dedicado aos oratorios domésticos presentes em casas e fazendas de províncias de São Paulo, o trabalho procura não apenas reconstruir a gestação formal dos oratórios, mas também identificar as autorizações formais concedidas pelo poder religioso para a instalação desses objetos em ambiente privado. Trata-se, portanto, de uma articulação entre elementos da antropologia, da história social e das religiões e da história dos objetos de arte e de devoção. Um grupo de investigadores que compartilham do mesmo espírito formou-se na Universidade Federal de Minas Gerais em torno de Adalgisa Arantes Campos, autora de A Terceira devoção do setecentos mineiro: o culto a São Miguel e Almas, um significativo estudo acerca dos rituais e das práticas relacionadas à morte bem como da organização das irmandades religiosas (CAMPos, 1994 $)^{11}$. Sobre esse mesmo assunto, destacamos também trabalhos recentes como A boa Morte e o bem morrer: culto, doutrina e icoonografia nas irmandades mineiras, de Sabrina Sant'anna (SANT'ANNA, 2006) e a tese de doutorado de Maria Regina Emery Quites sobre as imagens de vestir. Intitulada Imagem de vestir : revisão de conceitos através de estudo comparativo entre as Ordens Terceiras Franciscanas no Brasil (QUITES, 2006), essa pesquisa apresenta uma nova compreensão sobre esse gênero de escultura religiosa e sobre as atitudes a ele ligadas, expondo igualmente a necessidade da recuperação de uma história dos têxteis no Brasil e de sua integração ao processo de criação artística do barroco brasileiro. avança graças a investigações pontuais e estudos de caso. Esse foi o tema do quinto Colóquio Luso-Brasileiro de História da Arte, discutido em um volume organizado por Fausto Sanches Martins, Artistas e Artífices e a sua mobilidade no mundo de expressão portuguesa (SANCheS MARTINS, 2007). Em trabalho recente, Andre L. Tavares Pereira cuidou de ampliar a compreensão da trajetória de artistas como Manoel Dias de Oliveira - artista próximo de Domingos Antônio Sequeira, o principal pintor português de seu tempo - entre o Rio de Janeiro, Lisboa e Roma, bem como de suas articulações com o ambiente português no final do século XVIII (TAVARES, 2012). Estabelecida em Portugal, a pesquisadora Patrícia D. Telles, da Universidade de Évora, desenvolve uma pesquisa pioneira sobre a retratística portuguesa do final dos setecentos, recuperando assim um contexto não apenas pouco divulgado no âmbito brasileiro como também negligenciado com freqüência em Portugal (TELLES, 2013).

Outros pintores atuantes no final do século XVIII, particularmente na passagem ao século XIX, como João Francisco Muzzi, Leandro Joaquim ou o italiano Manoel Julião, têm recebido a atenção de pesquisadores como Valéria Piccoli e Luciano Migliaccio (MIGLIACCIO, 2007 ; PICCOLI, 2013). Enquanto este ultimo interessa-se pelo tema da criação da pintura de história no Brasil no início do século XIX, Jaelson Bitran Trindade (TRINDADE J., 1998) se dedica ao tema da formação e da profissionalização dos artistas no contexto colonial na mesma época. Aproveitamos para mencionar também o trabalho pioneiro realizado por Judith Martins, para a região de Minas Gerais (MARTINS J., 1974), Marieta Alves, para a Bahia (ALVES, 1976), e, mais recentemente, Vera Acioli, para Pernambuco (ACIOLY, 2008), na elaboração de dicionários de artistas atuantes entre os séculos XVII e XIX. O esforço enciclopédico de Carlos del Negro (DEL NEGRo, 1958), essencial para a compreensão do desenvolvimento da pintura em Minas Gerais, merece ser destacado, além de Carlos Ott (otT, 1982) e Clarival do Prado Valladares (VALLADARES, 
1982-1991), nomes capitais na definição da historiografia sobre a produção artística baiana do século XVII ao século XIX.

37 A história dos meios, das técnicas e dos materiais é um campo amplamente difundido entre os investigadores ligados aos principais centros de restauro, como é o caso do Centro de Conservação e Restauração da Universidade Federal de Minas Gerais. O trabalho de Renata Almeida Martins em Tintas da terra tintas do reino: arquitetura e arte nas Missões Jesuíticas do Grão-Pará (MARTINS R., 2009) oferece uma visão ampla sobre os meios de execução da obra de arte e sobre a adaptação de modelos visuais no âmbito dos colégios jesuítas do norte do Brasil entre os séculos XVII e XIX, no que era então o estado do Grão-Pará e Maranhão, uma das províncias aministrativas da América portuguesa. Seguindo sua investigação, a autora desenvolve uma nova pesquisa sobre o naturalista e correspondente da Academia Portuguesa de Ciência de Lisboa Alexandre Rodrigues Ferreira e sua obra mais importante, Viagem Filosófica, um amplo compêndio ilustrado sobre a sua expedição de 1783-1792 pela Amazônia e pelo o Mato Grosso que inclui notícias sobre a produção de pigmentos para pintura extraídos de plantas locais.

Pesquisas interdisciplinares conectando conhecimentos e competências em restauro, pesquisa histórica e gestão cultural são ainda raras. Apesar de louváveis iniciativas no sentido oposto, ainda sobrevive no Brasil uma divisão temática entre disciplinas como arquitetura, urbanismo, estudo da escultura religiosa (capitaneado pelo trabalho zeloso de instituições como o Centro de Estudos da Imaginária Brasileira), iconografia (como no trabalho de Maria Beatriz de Mello e Souza), ou estudos de cunho sociológico ou antropológico (SOUZA, 1999, p. 475-489). A tese de doutorado de Eliana Ambrósio, Presépio Napolitano do Museu de Arte Sacra de São Paulo e de coleções internacionais: cenografia e expografia (AMBRósio, 2012) é um dos casos em que se somam a acuidade da recontrução de imagens escultóricas dos séculos XVII e XVIII - no caso, um presépio de origem napolitana exposto no Museu de Arte Sacra de São Paulo -, reflexões sobre os eventuais resultados práticos da investigação sobre o contexto de produção das peças e a história da musealização dos presépios em coleções e conjuntos similares existentes no Brasil. Na mesma vertente, estabelecendo cruzamentos entre os campos da música, da ópera e da arquitetura teatral, Rosana Marreco Brescia inventaria e analisa os modelos de arquitetura dos teatros dos séculos XVIII e XIX no Brasil (BRESCIA, 2012). Todo o campo de investigação sobre os espetáculos e a música setecentista encontra-se em franca expansão no Brasil. Esse tema, assim como o das festividades coloniais, que foi objeto de um amplo debate ainda nos anos 1990, mereceria um capítulo à parte dada a sua complexidade (JANCSO, KANTOR, 2002).

As relações com a Itália têm sido abordadas também a partir de pesquisas sobre a presença, no contexto português dos setecentos, de artistas italianos como Vincenzo Baccherelli, e a respeito da difusão da pintura de quadratura, tema desenvolvido por pesquisadores como Magno Mello, da Universidade Federal de Minas Gerais (MELLo, 2007), e Giuseppina Raggi, Universidade Nova de Lisboa (RAGGI, 2003). O grande esforço de compreensão do legado do bolonhês Antônio José Landi em Belém, por meio da plataforma digital Forum Landi ${ }^{12}$, desenvolvida pela Universidade Federal do Pará, também é um passo importante para a compreensão dos processos de transferência artística ocorridos em meados do século XVIII. Ampliada por Nancy Davenport (DAVENPORT, 1975) e por Santiago Sebastián (SEBASTIÁN, 1989), a investigação sobre modelos iconográficos e sobre a circulação de gravuras, algo que depende de um amplo 
trabalho arquivístico - ainda em curso no Brasil -, também foi desenvolvida por investigadores como Pedro Queiroz Leite (LEITE, 2011).

Nesses últimos anos, o projeto "Barroco Global", fruto de uma colaboração entre várias instituições (Getty Research Institute, Zürich Universität, Universidade Federal de São Paulo), permitiu uma ampla discussão a respeito das atuais abordagens teóricas e metodológicas da história da arte em relação à questão da "arte mundial" e aos debates transculturais e transdisciplinares com outras áreas, como a teoria literária, a antropologia, etc. Essa ampliação permitiu inserir a arte colonial no contexto das discussões sobre a cultura ibérica. Além do projeto "Researching and Teaching Art History in a Global World", desenvolvido pelo departamento de história da arte da Universidade Federal de São Paulo em parceria com a Universidade de Zurique, podemos mencionar também o projeto "Hispanic Baroque", criado no Canadá. Essa inclusão abrange também a abordagem trans-histórica do neobarroco. Jens Baumgarten desenvolveu esses temas a partir de sua abordagem de "sistemas visuais" que inclui a arte colonial no Brasil e as transferências de conceitos e artefatos (BAUMGARTEN, 2010). Ele insere a arte brasileira da época colonial em um sistema global ao propor um conjunto de microteorias a partir do artefato.

41 O tema da formação artística antes da academia tem se ampliado consideravelmente. Ao trabalho basilar do português Rafael Moreira (MOREIRA, 1994) ou de Ana Maria Monteiro de Carvalho (CARVALHO, 1999), somam-se os novos esforços de compreensão do papel da engenharia militar para a formação de arquitetos e mestres brasileiros do século xVIII. O capítulo mais recente dessa história é a obra de Beatriz Piccoloto S. Bueno, Desenho e Desígnio: o Brasil dos engenheiros militares (BUENO, 2012).

A produção crítica e a pesquisa sobre o barroco no Brasil são campos vastos e dinâmicos. O tema, que já atraia o interesse de historiadores da arte no século XIX, transformou-se no século xx em uma grande área de interesse, símbolo da nação e da origem da especificidade estética brasileira, em uma operação que nem sempre foi regra para a produção artística latino-americana. A identificação do barroco com o nacional e os múltiplos debates sobre o tipo de intercâmbio com as fontes internacionais, assim como os sincretismos formais entre elementos locais e europeus, africanos ou asiáticos, recentemente ampliaram o debate, provocando assim uma revisão das abordagens tradicionais. Estas, por sua vez, transformam-se e aperfeiçoamse na medida em que dados referentes às artes dos séculos xVII e XVIII são progressivamente disponibilizados e a sistematizados. A nova produção acadêmica busca adaptar-se ao debate internacional, mas oferece, ao dedicar-se à análise da de uma produção artística complexa concebida em ambiente de superposição cultural intensa, novas vias de interpretação do material visual. Vista dessa perspectiva, essa seleção crítica de textos possibilita a compreensão do ritmo das inovações e das grandes linhas analíticas que definem a produção historiográfica e artística sobre um barroco necessariamente multiforme. 


\section{BIBLIOGRAFIA}

- Acioly, 2008: Vera Lúcia C. Acioly, A identidade da beleza: dicionário de artistas e artífices do século XVI ao XIX em Pernambuco, Recife, 2008.

- Aleijadinho..., 2002: Aleijadinho e Mestre Piranga: processos de atribuição e história da arte, Dalton Sala

E., (cat. expo., São Paulo, Pinacoteca do Estado de São Paulo, 2002-2003), São Paulo, 2002.

- ALVES, 1976: Marieta Alves, Dicionário de artistas e artífices na Bahia, Salvador, 1976.

- AMARAL, 1981: Aracy Amaral, A hispanidade em São Paulo: da casa rural à Capela de Santo Antônio, São Paulo, 1981.

- AMARAL, 1994: Aracy Amaral E., Arquitectura neocolonial: América Latina, Caribe, Estados Unidos, São Paulo, 1994.

- AMBRósio, 2012: Eliana Ribeiro Ambrósio, Presépio napolitano do Museu de Arte Sacra de São Paulo e de coleções internacionais: cenografia e expografia, tese de doutorado, Universidade Estadual de Campinas, 2012.

- ANDRADE, 1921: Mário de Andrade, “De São Paulo”, in Ilustração Brasileira, Fevereiro, 1921.

- ANDRADE, 1928: Mário de Andrade, “Aleijadinho: posição histórica”, in O Jornal, 1928.

- Arte barroca, 2000: Mostra do redescobrimento: Arte barroca, Nelson Aguilar, Myriam Andrade Ribeiro de Oliveira EE., (cat. expo., São Paulo, Bienal de São Paulo, 2000), São Paulo, 2000.

- BAETA, 2010: Rodrigo Espinha Baeta, O Barroco, a arquitetura e a cidade nos séculos XVII e XVIII, Salvador, 2010.

- BASTOS, 2009: Rodrigo Almeida Bastos, A maravilhosa fábrica de virtudes: o decoro na arquitetura religiosa de Vila Rica, Minas Gerais (1711-1822), tese de doutorado, Universidade Federal de São Paulo, 2009.

- BAUMGARTEN, 2010: Jens Baumgarten, “Staging Baroque Worship in Brazil”, in David Morgan E., Religion and Material Culture: The Matter of Belief, Londres/New York, 2010, p. 173-192.

- BAZIN, 1956-1958: Germain Bazin, L’Architecture religieuse baroque au Bresil, Paris, 1956-1958.

- BELOW, 2005: Ingrid Below, “'Jene widerspenstige Leichtigkeit der Innovation' Hanna Deinhards Wissenschaftskritik, Kunstsoziologie und Kunstvermittlung”, in Ursula Hudson-Wiedenmann, Beate Schmeichel-Falkenberg E., Grenzen Überschreiten: Frauen, Kunst und Exil, Würzburg, 2005, p. 151-179.

- BRANDÃo, 1998: Ângela Brandão, Abrasileirando a coisa lusa: O Aleijadinho pelo olhar de Mário de Andrade, Ouro Preto, 1998.

- Brazil: Body and Soul, 2001 : Brazil: Body and Soul, Edward J. Sullivan E., (cat. expo., New York, Guggenheim Museum, 2001-2002), New York, 2001.

- BRENNA, 1982-1983: Giovanna Rosso Brenna, "Medieval ou barroco? Proposta de leitura do espaço urbano colonial”, in Revista Barroco, 12, 1982-1983, p. 141-146.

- BRESCIA, 2012: Rosana Marreco Brescia, É lá que se representa a comédia: A Casa da Ópera de Vila Rica, 1770-1822, Jundiaí, 2012. 
- BRESSAN, 1997: Maria Lúcia Bressan, Modernizada ou Moderna? A arquitetura em São Paulo, 1938-45, tese de doutorado, Universidade Federal de São Paulo, 1997.

- BRESSAN, 2011: Maria Lúcia Bressan, Neocolonial, modernismo e preservação do patrimônio no debate cultural dos anos 1920 no Brasil, São Paulo, 2011.

- BUARQUe De HOLANDA, 1936: Sérgio Buarque de Holanda, Raízes do Brasil, Rio de Janeiro, 1936.

- BUENO, 2012: Beatriz Piccolotto Siqueira Bueno, Desenho e Desígnio: o Brasil dos engenheiros militares, 1500-1822, São Paulo, 2012.

- CAMPOS, 2005: Adalgisa Arantes Campos, Mestre Ataíde: aspectos históricos, estilísticos, iconográficos e técnicos, Belo Horizonte, 2005.

- CARMO, 1999: Rogério Amorim do Carmo, Ouro Preto: experiência imaginária da paisagem e gesto projetual, dissertação de mestrado, Universidade Federal do Rio de Janeiro, Faculdade de Arquitetura e Urbanismo, Programa de Pós-Graduação em Urbanismo, 1999.

- CARVAlHo, 1999: Anna Maria Fausto Monteiro de Carvalho, Mestre Valentim, São Paulo, 1999.

- CHIARELl, 2007: Tadeu Chiarelli, Pintura não é só beleza: a crítica de arte de Mário de Andrade, Florianópolis, 2007.

- CAMPos, 1994: Adalgisa Arantes Campos, A terceira devoção do setecentos mineiro: o culto a São Miguel e Almas, tese de doutorado, Universidade Federal de São Paulo, 1994.

- CAMPos, 2005: Adalgisa Arantes Campos, Manoel da Costa Ataíde: aspectos históricos, estilísticos, iconográficos e técnicos, Belo Horizonte, 2005.

- Costa, (1941) 1997: Lucio Costa, “A arquitetura dos jesuítas no Brasil”, in Revista do Patrimônio Histórico e Artístico Nacional, 26, (1941) 1997, p. 105-169;

- DACOSTA KAUfMAnN, 2004: Thomas DaCosta Kaufmann, Towards a Geography of Art, Chicago, 2004.

- DANTAS, 2004: Leonardo Dantas, Pernambuco Preservado, Recife, 2004.

- DAVENPORT, 1975: Nancy Davenport, "European sources for the prophets at Congonhas do Campo", in Revista Barroco, 7, 1975, p. 407-421.

- DE CAMPOS, 1979: Haroldo de Campos, "Ruptura dos gêneros na literatura latino-americana", in César Fernández Moreno E., América Latina em sua literatura, São Paulo, 1979, p. 281-305.

- DE CAMPOS, 1989: Haroldo de Campos, O sequestro do barroco na formação da literatura brasileira: o caso Gregório de Matos, Salvador, 1989.

- DEINHARD, 1967: Hanna Deinhard, Bedeutung und Ausdruck, Neuwied/Berlin, 1967.

- DEL NEGRo, 1958: Carlos Del Negro, Contribuição ao estudo da pintura mineira, Rio de Janeiro, 1958.

- ETZEL, 1974: Eduardo Etzel, O Barroco no Brasil: psicologia - remanescentes em São Paulo, Goiás, Mato Grosso, Paraná, Santa Catarina, Rio Grande do Sul, São Paulo, 1974.

- FONSECA, 2001: Sônia Maria Fonseca, A invenção do Aleijadinho: historiografia e colecionismo em torno de Antônio Francisco Lisboa, dissertação de mestrado, Universidade Estadual de Campinas, 2001.

- FONSECA, 2003: Cláudia Damasceno Fonseca, Des terres aux villes de l'or : pouvoirs et territoires urbains au Minas Gerais, Brésil, XVIII ${ }^{e}$ siècle, Paris, 2003.

- FLEXOR, 1974: Maria Helena Ochi Flexor, Oficiais mecânicos na cidade do Salvador, Salvador, 1974.

- FLEXOR, 2009: Maria Helena Ochi Flexor, Mobiliário baiano, Brasília, 2009. 
- FLEXOR, 2011:Maria Helena Ochi Flexor, Igrejas e conventos da Bahia, Brasília, 2011.

- FREIRE, 2006: Luiz Alberto Ribeiro Freire, A Talha neoclássica na Bahia, Rio de Janeiro, 2006.

- FROTA, 1982: Lélia Coelho Frota, Ataíde: vida e obra de Manoel da Costa Ataíde, Rio de Janeiro, 1982.

- GOMES, 1988: Paulo Varela Gomes, A cultura arquitectónica e artística em Portugal no século XVIII, Lisboa, 1988.

- GOMES JÚNIOR, 1998: Guilherme Simões Gomes Júnior, Palavra peregrina: O Barroco e o pensamento sobre artes e letras no Brasil, São Paulo, 1998.

- GRAMMONT, 2008: Guiomar de Grammont, O Aleijadinho e o aeroplano: O Paraíso e a construção do herói colonial, Rio de Janeiro, 2008.

- GUERRA, 1989: Fernando Guerra, A igreja de São Pedro dos clérigos do Recife, Recife, 1989.

- HANSEN, 1987: João Adolfo Hansen, Alegoria: construção e interpretação da metáfora, São Paulo, 1987.

- HANSEN, 1989: João Adolfo Hansen, A sátira e o engenho: Gregório de Matos e a Bahia do século XVII, São Paulo, 1989.

- HANSEN, 1992: João Adolfo Hansen, “Colonial e barroco”, in Jayme Salomão E., América: descoberta ou invenção, (colóquio, Rio de Janeiro, 1992), Rio de Janeiro, 1992, p. 347-361.

- HANSEN, 2003 : João Adolfo Hansen, “Barroco, neobarroco e outras ruínas”, in Estudios Portugueses, 3, 2003, p. 171-217.

- JANCSO, KANTOR, 2002: István Jancsó, Iris Kantor E., Festa: cultura e sociabilidade na América portuguesa, (colóquio, São Paulo, 1999), São Paulo, 2001.

- KUBLER, 1959: George Kubler, The Art and Architecture of Spain and Portugal and Their American Dominions, Baltimore, 1959.

- KUBLER, 1962: George Kubler, The Shape of Time, New Haven, 1962.

- LEITE, 2011: Pedro Queiroz Leite, “O Missal da Régia Officina Typographica e seu legado na pintura Rococó mineira: uma refutação à influência de Bartolozzi”, in Anais do VII Encontro de História da Arte da UNICAMP, Campinas, 2011, p. 405-415, disponível em: http://www.unicamp.br/ chaa/eha/atasIIIeha.html (Acesso em: 10 novembro 2013).

- Lemos, 1979: Carlos Lemos, A casa colonial Paulista, São Paulo, 1979.

- Lemos, 1999: Carlos Lemos, A imaginária paulista, São Paulo, 1999.

- Leon et al., 1998: , Fernando Ponce de Leon et al., História da arte luso-brasileira: guia bibliográfico, Recife, 1998.

- Leon, Gaspar, 1998: Fernando Ponce de León, Lúcia Gaspar, História da arte luso-brasileira: Guia bibliográfico, Recife, 1998.

- Levy, 1936: Hanna Levy, Henri Wölfflin, sa théorie, ses prédécesseurs, (tese de doutorqdo, faculté des lettres de l'université de Paris, 1936), Rotweil, 1936.

- Levy, 1940: Hanna Levy, "Valor artístico e valor histórico: importante problema da história da arte”, in Revista do patrimônio histórico e artístico nacional, 4, 1940, p. 181-192.

- Levy, 1941: Hannah Levy, "A propósito de três teorias sobre o barroco", in Revista do patrimônio histórico e artístico nacional, 5, 1941, p. 250-284.

- Levy, 1942: Hannah Levy, “A pintura colonial no Rio de Janeiro”, in Revista do patrimônio histórico e artístico nacional, 6, 1942, p. 7-79. 
- Levy, 1944: Hannah Levy, "Modelos Europeus na pintura colonial”, in Revista do patrimônio histórico e artístico nacional, 8, 1944, p. 7-66.

- Levy, 1945: Hannah Levy, "Retratos coloniais", in Revista do patrimônio histórico e artístico nacional, 9, 1945, p. 251-290.

- MACHADO, 1969: Lourival Gomes Machado, “Teorias do Barroco”, in MACHADO, 1969, p. 29-78.

- MACHADO, 1969: Lourival Gomes Machado, Barroco mineiro, São Paulo, 1969.

- MARINS, 2001: Paulo C. Garcez Marins, Através da rótula: sociedade e arquitetura no Brasil, séculos XVII a Xx, São Paulo, 2001.

- MARTINS J., 1974: Judith Martins, Dicionário de artistas e artífices dos séculos XVIII e XIX em Minas Gerais, Rio de Janeiro, 1974.

- MARTINS R., 2009: Renata Maria de Almeida Martins, Tintas da terra tintas do reino: arquitetura e arte nas Missões Jesuíticas do Grão-Pará, tese de doutorado, Universidade Federal de São Paulo, 2009.

- MASSIMI, 2012: Marina Massimi E., A novela história do predestinado peregrino e seu irmão Precito (1682): compêndio dos saberes antropológicos e psicológicos dos jesuítas no Brasil colonial, São Paulo, 2012.

- MATOS, 2007a: Eusébio de Matos, Ecce Homo, Porto Alegre, publicado no século XVII, 2007.

- MATOS, 2007b: Eusébio de Matos, A Paixão de Cristo Senhor Nosso: desde a instituição do sacramento na ceia até a lastimosa soledade de Maria Santíssima, José Américo Miranda, Nilton de Paiva Pinto E., Belo Horizonte, publicado no século xvII, 2007.

- MELLO, 2007: Magno Mello, "Retórica e persuasão na arte barroca: o teto da igreja do seminário jesuítico em Santarém”, in Anais do III Encontro de História da Arte da UNICAMP, 2007, p. 418-430.

- MENEZES, 1984: José Luiz da Mota Menezes, Dois monumentos do Recife, Recife, 1984.

- MENEZES, 1988: José Luiz da Mota Menezes, Atlas histórico cartográfico do Recife, Recife, 1988.

- MIGLIACCIO, 2007: Luciano Migliaccio, Arte brasiliana del XIX seccolo, Udine, 2007.

- MONTEZUMA, 2002: Roberto Montezuma, Arquitetura Brasil 500 anos: uma invenção recíproca, Recife, 2002.

- MOREIRA, 1994: Rafael Moreira E., A Arquitectura militar na expansão portuguesa, Lisbonne, 1994.

- MORESCHI, 2004: Marcelo S. Moreschi, A Inclusão de "barroco" no Brasil: o caso dos catálogos, dissertação de mestrado, Universidade Estadual de Campinas, 2004.

- MOSER, 2001: Walter Moser, "Résurgences et valences du baroque", in Résurgences baroques: trajectoires d'un processus transculturel, Bruxelles, 2001, p. 25-44.

- MUHANA, 2002: Adma Muhana, Poesia e pintura ou Pintura e poesia: tratado seiscentista de Manuel Pires de Almeida, São Paulo, 2002.

- Negro de corpo..., 2000: Mostra do redescobrimento: negro de corpo e alma, Nelson Aguilar, Emanoel Araújo E., (cat. expo., São Paulo, Bienal de São Paulo, 2000), São Paulo, 2000.

- OLIVEIRA, 2003: Myriam Andrade Ribeiro de Oliveira, O Rococó religioso no Brasil e seus antecedentes europeus, São Paulo, 2003.

- OTT, 1982: Carlos Ott, A escola baiana de pintura: 1764/1850, São Paulo, 1982. 
- O Universo..., 1998: O Universo mágico do barroco brasileiro, Emanoel Araújo E., (cat. expo., São Paulo, Galeria de Arte do SESI, 1998), São Paulo, 1998.

- PÉCORA, 2001: Alcir Pécora, Máquina de gêneros: novamente descoberta e aplicada a Castiglione, Della Casa, Nóbrega, Camões, Vieira, La Rochefoucauld, Gonzaga, Silva Alvarenga e Bocage, São Paulo, 2001.

- PÉCORA, 1994: Alcir Pécora, Teatro do sacramento: a unidade teológico-retórico-política dos sermões de Antonio Vieira, Campinas, 1994.

- PICCOLI, 2013: Valeria Piccoli, “Carlos Julião e o desenho etnográfico no mundo português”, in Camila Dazzi, Isabel Portella, Artur Valle E., Oitocentos: intercâmbios culturais entre Brasil e Portugal, Rio de Janeiro, 2013, p. 496-508.

- PIO, 1957: Fernando Pio, A ordem terceira de São Francisco do Recife, Recife, 1957.

- QUITES, 2006: Maria Regina E. Quites, Imagem de vestir: revisão de conceitos através de estudo comparativo entre as ordens terceiras franciscanas no Brasil, tese de doutorado, Universidade Estadual de Campinas, 2006.

- RAGGI, 2003: Giusepina Raggi, "Pinturas de fundais e falsos interiores : Decorações pictóricas integrais de Pasquale Parente", in Revista Monumentos, 18, 2003.

- REIS FILHO, 2000: Nestor Goulart Reis Filho, Contribuição ao estudo da evolução urbana do Brasil, 1500-1720, São Paulo, 2000.

- REIS FILHO, 2001: Nestor Goulart Reis Filho, Imagens de Vilas e cidades no Brasil Colonial, São Paulo, 2001.

- Robert C. Smith, 2000: Robert C. Smith, 1912-1975: a investigação na história da arte, Manuel da Costa Cabral, Jorge Rodrigues E., (cat. expo., Lisboa, Fundação Calouste Gulbenkian, 2000), Lisboa, 2000.

- ROSSA, 2002: Walter Rossa, A Urbe e o traço, Coimbra, 2002.

- RUSSo, 2010: Silveli Maria de Toledo Russo, Espaço doméstico, devoção e arte: a construção histórica do acervo de oratórios brasileiro, séculos XVIII e XIX, tese de doutorado, Universidade Federal de São Paulo, 2010.

- SAIA, 1978: Luís Saia, Morada Paulista, São Paulo, 1978.

- SANCHES MARTINS, 2007 : Fausto Sanches Martins, Artistas e artífices e a sua mobilidade no mundo de expressão portuguesa, (colloque, Porto, 2005), Porto, 2007.

- SANT'ANNA, 2006: Sabrina Mara Sant'anna, A boa morte e o bem morrer: culto, doutrina, iconografia e irmandades mineiras (1721 a 1822), tese de doutorado, Universidade Federal de Minas Gerais , 2006.

- SANTOS, 1951: Paulo Santos, O barroco e o jesuítico na arquitetura brasileira, Rio de Janeiro, 1951.

- SANTOS, 2001: Paulo Santos, Formação de cidades no Brasil Colonial, Rio de Janeiro, 2001.

- SEBASTIÁN, 1989: Santiago Sebastián, Contrareforma y barroco: lecturas iconográficas y iconológicas, Madrid, 1989.

- SoUZA, 1999: Maria Beatriz de Mello e Souza, Les Images de la Vierge Marie au Brésil colonial: Brésil Baroque. Entre Ciel et Terre, Paris, 1999.

- TAVARES, 2012: André L. Tavares Pereira, “Displaying the Traslatio Imperii: Roman Art and Iconography between Portugal and Portuguese America in late 18th century", in Giovanna Capitelli, Stefano Grandesso, Carla Mazzarelli E., Roma fuori di Roma: l'esportazione dell'arte moderna da Pio VI all'Unità, 1775-1870, Rome, 2012, p. 323-333. 
- TEIXEIRA, 1999: Ivan Teixeira, Mecenato pombalino e poesia neoclássica: Basilio da Gama e a poética do encômio, São Paulo, 1999.

- TELLES, 2013: Patrícia Delayti Telles, « Brasil e Portugal à sombra de Saint-Sulpice: Retrato dos viscondes da Pedra Branca com a sua filha », in Oitocentos: intercâmbios culturais entre Brasil e Portugal, (colóquio, Rio de Janeiro, 2012), Rio de Janeiro, 2013, p. 412-423.

- TIRAPELLI, 2003: Percival Tirapelli, Igrejas paulistas: barroco e rococó, São Paulo, 2003.

- Tradição e Ruptura, 1984: Tradição e ruptura: síntese da arte e cultura brasileira, (cat. expo., São Paulo, Fundação Bienal de São Paulo, 1984-1985), São Paulo, 1984.

- TRINDADE C., 1958: Cônego Raimundo Trindade, São Francisco de Assis de Ouro Preto, Rio de Janeiro, 1958.

- TRINDADE J., 1998: Jaelson Bitran Trindade, “Corporação e as Artes Plásticas: o Pintor, de Artesão a Artista", in 0 universo..., 1998, p. 246-269.

- VALLADARES, 1982-1991: Clarival do Prado Valladares, Nordeste histórico e monumental, Salvador, 1982-1991.

- VASCONCELlos, 1968: Sylvio de Vasconcellos, Minas: cidades barrocas, São Paulo, 1968.

- WARNKE, 1989: Martin Warnke, “On Heinrich Wölfflin”, in Representations, 27, 1989, p. 172-187.

\section{NOTAS}

1. A vasta produção das universidades, sobretudo brasileiras, de teses de doutorado e dissertações de mestrado não foi considerada aqui devido ao acesso restrito a esses textos.

2. Cornelius Gurlitt, Geschichte des Barockstiles, des Rococo und des Klassicismus in Belgien, Holland, Frankreich, England, Stuttgart, 1887-1889; Heinrich Wölfflin, Renascença e Barroco, São Paulo, 2005 [ed. orig.: Renaissance und Barock, Munich, 1888]; Conceitos fundamentais da história da arte : o problema da evolução dos estilos na arte mais recente, São Paulo, 2006 [ed. orig.: Kunstgeschichtliche Grundbegriffe: Das Problem der Stilentwickelung in der neueren Kunst, Munich, 1915].

3. Jacob Burckhardt, Wilhelm Lübke, Geschichte der neueren Baukunst, Stuttgart, 1904 ; Wölfflin, (1888) 1961, citação no 2 ; BAZIN, 1956-1958 ; Walter Benjamin, Ursprung des deutschen Trauerspiels, Berlin 1928 ; Omar Calabrese, L'età neobarocca, Bari, 1987.

4. A partir de seu artigo de 1941 (LEVY, 1941), Hannah Levy passou a escrever o seu nome com um " $h$ " no final.

5. Esses artigos podem ser vistos como uma tese de livre-docência.

6. Neste contexto, gostaria de lembrar a proeminente obra de Carl Einstein, Die Negerplastik (Leipzig, 1915) que propõe uma análise da arte africana livre de exotismos, encaixando-se assim nos padrões de uma nova interpretação.

7. Machado não considerou os desdobramentos da teoria de Levy que culminaram na publicação de Bedeutung und Ausdruck, de Hanna Deinhard (DEINHARD, 1967).

8. Edward Said, Orientalismo: o oriente como invenção do ocidente, São Paulo, 1990 [ed. orig.: Orientalism: Western Representations of the Orient, Londres, 1978]; Homi Bhabha, Nation and Narration, Londres, 1990; Homi Bhabha, O Local da Cultura, Belo Horizonte, 1998 [ed. orig. : The Location of Culture, Londres/New York, 1994].

9. Jaynie Anderson E., Crossing Cultures: Conflict, Migration and Convergence, (colóquio, Melbourne, 2008), Carlton, 2009.

10. David Summers, Real Spaces: World Art and the Rise of Western Modernism, Londres/New York, 2003; Thomas DaCosta Kaufmann, Toward a Geography of Art, Chicago/Londres, 2004. 
11. Recentemente, a autora organizou a publicação de um dossiê sobre Manoel da Costa Ataíde que se tornou o estudo mais completo sobre a obra do pintor mineiro, ampliando as investigações anteriores, como as de Lélia Coelho Frota (FROTA, 1982 ; CAMPOS, 2005).

12. Disponível em: http://ufpa.br/forumlandi (Acesso em: 10 novembro 2013). 